\title{
Epidemiology of kidney failure with replacement therapy in Puerto Rico: Report from 2001 to 2017
}

\author{
Johanna K. Corchado-Feliciano ${ }^{1 *}$, Ángela Diaz , Beatriz Zayas², Samuel A. Collazo-Meléndez², \\ Jesús D. Vega-Colon², Angélica Ortiz², Tatiana Correa², Carlos Rivera-Bermúdez², \\ Ileana Ocasio-Meléndez ${ }^{2}$, and José L. Cangiano² \\ ${ }^{1}$ Renal Council of Puerto Rico Inc.; ${ }^{2}$ Department of Internal Medicine, Nephrology Section, University of Puerto Rico, Medical Sciences Campus. \\ San Juan Puerto Rico, Puerto Rico
}

\begin{abstract}
Kidney failure (KF) with replacement therapy (RT) is a major health threat to Latin American population. Studies comparing the Latin American population in different countries have ascertained the growing concern of increased incidence and prevalence. Some factors that contribute to this condition are diabetes, hypertension, and poverty. Objective: The purpose of this study was to report the epidemiology for KF with RT in Puerto Rican population from 2001 to 2017. Materials and methods: Data were provided by the Renal Council of Puerto Rico from 2001 to 2017. Population involved adult male and women residents of Puerto Rico registered as dialysis patients. Methods for reporting data incorporated formulas for calculating incidence, prevalence, and mortality rate per year. Results: The incidence rate demonstrated an increase from 306 per million population (pmp) in 2001 to $419 \mathrm{pmp}$ in 2016. Prevalence rate reported as $892 \mathrm{pmp}$ at the start of the study and $1598 \mathrm{pmp}$ at the end. The mortality rate was reported as $255 \mathrm{pmp}$ in 2001 and progressively increased to $345 \mathrm{pmp}$ in 2017. Conclusions: This study demonstrates the increasing trend of the incidence and prevalence among cases of KF in Puerto Rico. Reporting the above statistical data will help provide an understanding of which health programs and strategies are needed to prevent this condition.
\end{abstract}

Key words: Incidence. Prevalence. Mortality. Kidney failure. Puerto Rican and Latin American population.

\section{Epidemiología de enfermedad renal crónica en Puerto Rico: informe de 2001-2017}

\section{Resumen}

La enfermedad renal crónica (ERC) con tratamiento renal sustitutivo (TRS) es una amenaza para la población latinoamericana. Estudios que comparan la población latinoamericana en diferentes países han determinado la creciente preocupación de mayor incidencia y prevalencia. Algunos factores que contribuyen a esta condición son diabetes, hipertensión, pobreza. Objetivo: El propósito de este estudio fue reportar la epidemiología para la ERC con TRS en la población puertorriqueña desde 2001-2017. Materiales y métodos: Los datos fueron proporcionados por el Consejo Renal de Puerto Rico desde 2001 a 2017. Las características de la población involucraron hombres y mujeres adultos residentes de Puerto Rico registrados como pacientes de diálisis. Los métodos para informar datos incorporaron fórmulas de incidencia, prevalencia y mortalidad por año. Resultados: La tasa de incidencia demostró un aumento de 306 pmp en 2001 a 419 pmp en 2016. La tasa de

\section{Correspondence to:}

*Jesús D. Vega-Colon

E-mail: jesus.vega6@upr.edu
Date of reception: 01-06-2020

Date of acceptance: 24-08-2020

DOI: 10.24875/NEFRO.20000019
Disponible en internet: 17-12-2020 Nefro Latinoam. 2020;17:95-99 www.nefrologialatinoamericana.com license (http://creativecommons.org/licenses/by-nc-nd/4.0/). 
prevalencia se informó como $892 \mathrm{pmp}$ al comienzo del estudio y 1,598 pmp al final. La tasa de mortalidad se informó como 255 pmp en 2001 y aumentó progresivamente a 345 pmp en 2017. Conclusiones: Este estudio demuestra la tendencia creciente entre los casos de la ERC con TRS en Puerto Rico. Informar los datos estadísticos anteriores ayudará a comprender qué programas de salud son necesarios para prevenir esta condición.

Palabras claves: Incidencia. Prevalencia. Mortalidad. Enfermedad renal crónica. Población en Puerto Rico y Latinoamerica.

\section{Introduction}

Kidney failure (KF) with replacement therapy (RT) is a major health threat to the Latin American population, including Puerto Ricans. Several studies comparing the Latin American population in different countries have ascertained the growing concern of increased incidence and prevalence among Puerto Ricans ${ }^{1-3}$. It has been reported that, as a whole, Puerto Ricans have a worse health status than Mexicans and Cuban Americans ${ }^{4}$. Various factors contribute to this dismal health condition, including diabetes mellitus (DM), hypertension, poverty, language barrier, and lack of education ${ }^{3,4}$. The incidence and prevalence of KF with RT in Puerto Rico is high as in the United States of America; however, DM seems to be the primary diagnosis in Puerto Rico as $67 \%$ of the patients in hemodialysis have DM as their primary cause. Furthermore, when compared to the rest of Latin America, Puerto Rico reported the highest incidence rate (432.9 per million population [pmp]) and percentage (66.9\%) of new diabetic renal RT (RRT) patients'. In addition, Puerto Rico has the highest prevalence rate of total RRT among Latin American countries (1846.7 pmp), correlating with a higher gross national income and life expectancy at birth'.

In 2017, the prevalence of DM in Puerto Rico was reported to be $15-17.2 \%$; in contrast, in the US, it has been reported to be $9.4 \%$ in the general population ${ }^{5}$. In addition, the prevalence of hypertension, a risk factor for $\mathrm{KF}$ with RT, in Puerto Ricans has been reported to be $15 \%$ in 1994 and has remain escalating since then ${ }^{6,7}$. It has been reported to increase with age and has continued to show an increasing trend through the years, showing 39\% prevalence in recent studies performed on the island ${ }^{8}$. Knowledge of the risk factors involved in the increasing trend of $\mathrm{KF}$ with RT is of utmost importance to design strategies of health programs to prevent and adequately treat these conditions. The significance of this study is to determine the increasing trend of KF with RT that has been observed in the Puerto Rican population from 2001 to 2017.

\section{Materials and methods}

This study originated from clinical data collected by the Renal Council of Puerto Rico with information provided by the Quality Insight Renal Network 3 from 2001 to 2017 from dialysis patients. Characteristics of the subject population involved only adult male and female residents of Puerto Rico registered as dialysis patients on hemodialysis or peritoneal dialysis modality. Persons with chronic kidney disease (CKD) Stage I-IV and transplant modality were excluded. Furthermore, Puerto Rican persons who do not reside in the island during the time period mentioned and $\mathrm{KF}$ with RT patients that were not registered with Medicare and Medicaid Services (CMS) were not included. All clinical data utilized during the study did not contain any identifier that can be linked to the subjects.

The incidence rate of KF with RT is defined as the number of new patients with KF with RT in 1 year divided by the total population of $P R$ in the same year pmp. The prevalence rate is defined as the number of existing patients with KF with RT in 1 year divided by the total population of PR in the same year pmp. Mortality rate is defined as the number of deaths of patients with KF with RT in 1 year divided by the total population of PR in the same year pmp. Mortality was obtained from death certificates of the department of health.

\section{Statistical analysis}

The trends overtime in prevalence and mortality (Figs. 1 and 2) were examined using Joinpoint regression. These were based on Poisson regression using the Joinpoint 4.8.0.1 software ${ }^{9}$. The trends overtime were presented as annual percentage change with $95 \%$ confidence interval.

\section{Results}

Table 1 illustrates that the incidence has steadily increased from $306 \mathrm{pmp}$ in 2001 to $419 \mathrm{pmp}$ in 2016. The incidence of the year 2017 was not included due to a disruption of data recollection caused by the aftermath of Hurricane Maria. The prevalence was obtained from 2001 to 2017 and has been reported as $892 \mathrm{pmp}$ at the start of the study and $1598 \mathrm{pmp}$ at the end, showing an increase of $79.2 \%$. 


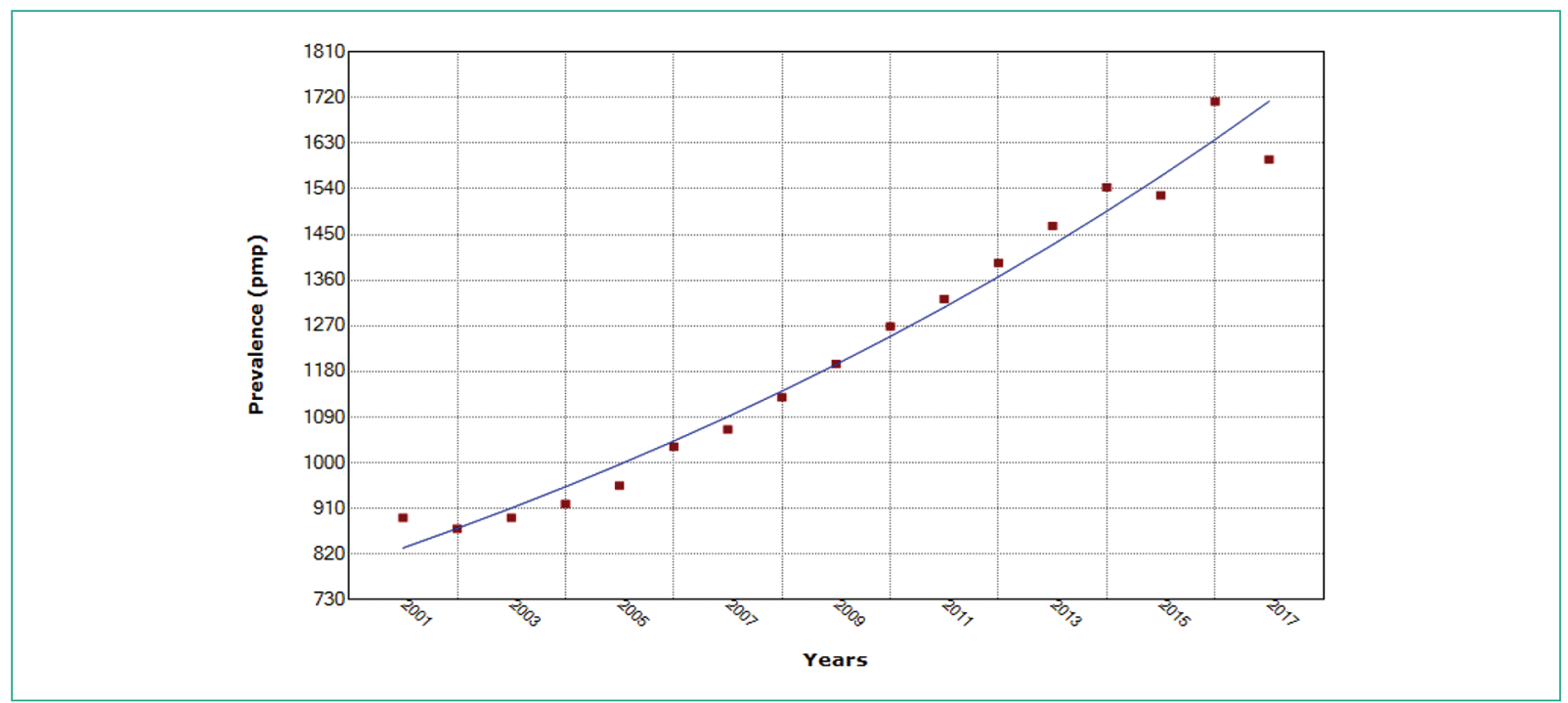

Figure 1. Trend in the prevalence of dialysis patients per million population from the year 2001 to 2017.

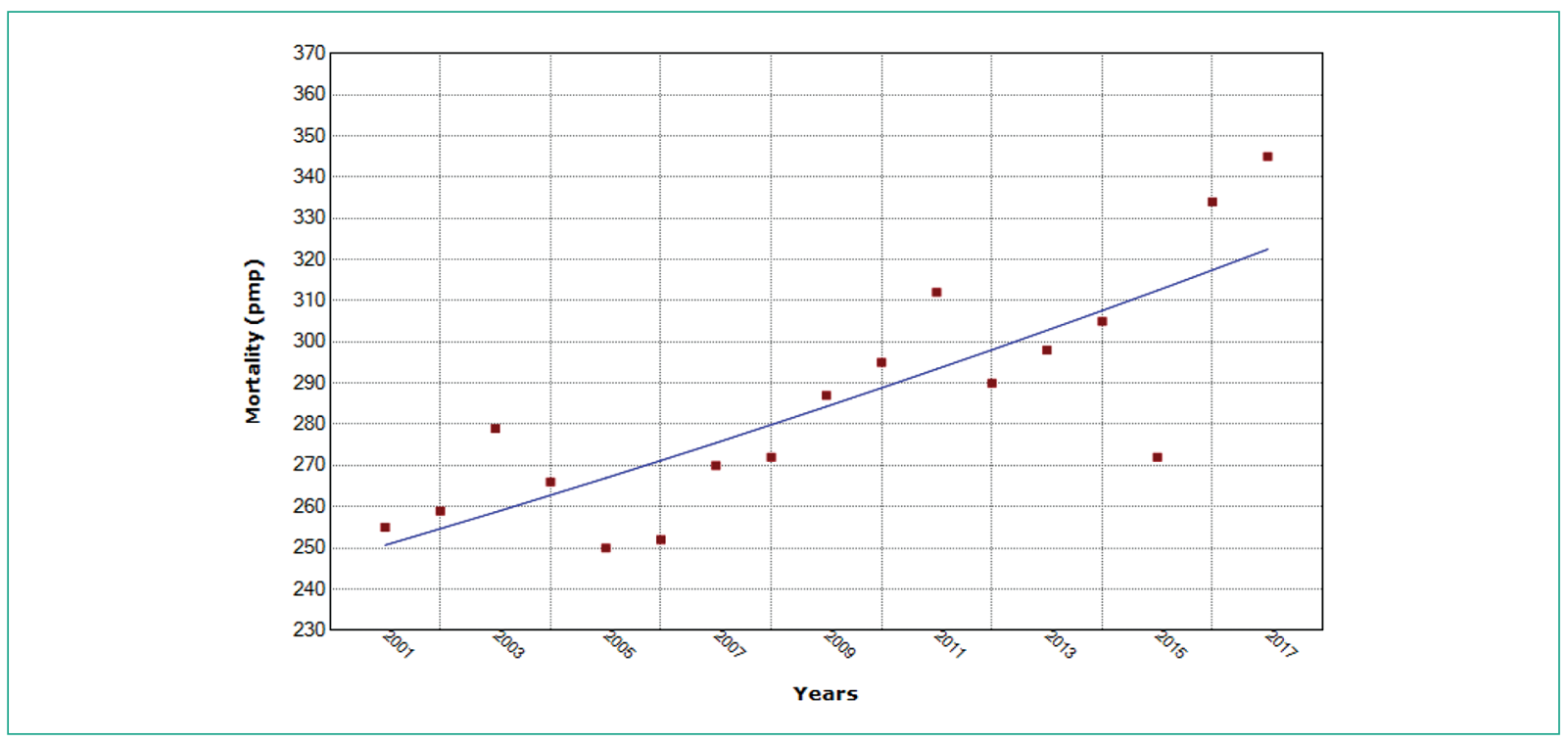

Figure 2. Trend in mortality of dialysis patients per million population from the year 2001 to 2017 .

Accordingly, the mortality rate was reported as 255 pmp in 2001 and progressively increased to $345 \mathrm{pmp}$ in 2017 , an increase of $35.3 \%$. An important point to highlight is that the mortality rate reached its highest point in over 15 years in 2016 and again in 2017.

Figures 1 and 2 demonstrated the trends in the prevalence and mortality of dialysis patients pmp from period 2001 to 2017 using Joinpoint regression statistical analysis. Similar to Table 1, an increasing tendency pattern is visualized through the years.

\section{Discussion}

The epidemiology of RRT for KF in a specific country is largely influenced by the causes of KF, availability of kidney centers, and the national wealth ${ }^{10-12}$. Our study demonstrates a steady increase in the prevalence, incidence, and mortality for RRT in KF in Puerto Rico from the year 2001 to 2017. The increasing trend has been associated to different inherent factors related to the ethnicity, life expectancy, clinical characteristics, 
Table 1. Incidence, prevalence, and mortality rates of dialysis patients in Puerto Rico per million population and number of cases (new and existing) from 2001 to 2017

\begin{tabular}{|l|l|l|l|l|l|l|}
\hline Years & Number of new cases & Incidence (pmp) & Number of existing cases & Prevalence (pmp) & Number of deaths & Mortality (pmp) \\
\hline 2001 & 1169 & 306 & 3408 & 892 & 975 & 255 \\
\hline 2002 & 1229 & 321 & 3325 & 870 & 991 & 259 \\
\hline 2003 & 1310 & 342 & 3411 & 892 & 1066 & 279 \\
\hline 2004 & 1278 & 334 & 3517 & 919 & 1017 & 266 \\
\hline 2005 & 1216 & 318 & 3649 & 955 & 955 & 250 \\
\hline 2006 & 1317 & 346 & 3928 & 1032 & 959 & 252 \\
\hline 2007 & 1346 & 356 & 4032 & 1066 & 1021 & 270 \\
\hline 2008 & 1337 & 356 & 4246 & 1129 & 1024 & 272 \\
\hline 2009 & 1370 & 366 & 4470 & 1195 & 1073 & 287 \\
\hline 2010 & 1475 & 396 & 4724 & 1269 & 1096 & 295 \\
\hline 2011 & 1446 & 392 & 4879 & 1323 & 1150 & 312 \\
\hline 2012 & 1498 & 411 & 5076 & 1394 & 1056 & 290 \\
\hline 2013 & 1425 & 396 & 5275 & 1467 & 1071 & 298 \\
\hline 2014 & 1499 & 408 & 5476 & 1543 & 1083 & 305 \\
\hline 2015 & 1360 & 368 & 5651 & 1527 & 1007 & 272 \\
\hline 2016 & 1428 & 419 & 5841 & 1712 & 1140 & 334 \\
\hline 2017 & Not informed & Not informed & 5334 & 1598 & 1151 & 345 \\
\hline
\end{tabular}

pmp: per million population.

poverty, and lack of education. Another factor of importance is that the availability of dialysis centers in the island has grown significantly through the years and there are now 45 dialysis centers in different communities from 2001 to 2017.

Puerto Rico is an island in the Caribbean (100 miles long by 35 miles wide) with a population of 3 million inhabitants with Spanish as the main language. According to the national census, most Puerto Ricans racially identify themselves as White, but there has been a trend to racial mixture (mulatto), which may predispose to the increasing CKD (African-Americans are more prone to CKD). At present, $10 \%$ of our population has CKD as detected by renal function determinations using standard formulas of measuring estimated glomerular filtration rate (eGFR) and/or proteinuria. As a requisite imposed by law, all laboratories must calculate eGFR in their routine reports of serum creatinine and make them available to all physicians for proper staging of CKD. Moreover, life expectancy has steadily increased, more for females than males. As mentioned before, DM has become an epidemic and increased prevalence in this condition has been recently reported as $15-17.2 \%$ of our population ${ }^{5}$. Hypertension has been associated to CKD as a cause and important factor in its progression. Similarly, obesity has become an additional contributing factor for the development of KF with RT and close to $40 \%$ of our population is overweight or obese. In fact, the metabolic syndrome, a condition characterized by insulin resistance, DM, hypertension, and a lipid derangement profile has been identified in $43 \%$ of our population ${ }^{13,14}$.

Another important factor is that in Puerto Rico, close to $50 \%$ of the population lives in the category of poverty which could lead to the lack of proper health care and education.

The relationship of the United States of America (USA) and Puerto Rico has been described as a commonwealth or territorial possession in which Puerto Ricans are categorized as residents of the USA with 
certain benefits, which include health-care programs such as Medicare and Medicaid. Dialysis and transplant services are paid by these programs since 1972. Patients with KF with RT are covered for $80 \%$ of services; the other $20 \%$ is covered by a coinsurance or by the patient.

In Latin America, many countries have a universal health plan which covers most of the patients with KF with RT, but some countries cannot afford to pay for these costly procedures. This consideration should be taken into account when you compare the epidemiology in Puerto Rico to Latin America and Europe.

The study of Luxardo et al..$^{15}$ has compared the prevalence of RRT for KF in Latin America (Puerto Rico included) and Europe between years 2004 and 2013. In 2013, the incidence was $181 \mathrm{pmp}$ in Latin America and 130 pmp for Europe. Similarly, the prevalence was 660 pmp for Latin America and 782 pmp for Europe with an increase of $4.0 \%$ and $2.2 \%$, respectively. The crude mortality rate was higher in Latin America (112 vs. 100 deaths per 1000 patient-years). Noteworthy, this study also described that Puerto Ricans had a very high unadjusted incidence rate compared to other Latin American countries except for Mexico and Panama. The department of health of Puerto Rico has been tracking CKD and KF with RT in different regions of the island with the use of eGFR, blood pressure, and blood sugar determinations.

\section{Conclusions}

This study demonstrates the increasing tendency of KF requiring RRT in Puerto Rico through the period of 2001-2017. The increasing trend on the incidence, prevalence, and mortality must be considered an alarming situation comprising a social and economic burden.

Compared to the Latin American countries and Europe, the Puerto Rican population is among the most affected with an increasing trend of RRT and mortality.

Today, the health authorities have the necessary information to design strategies of health programs to prevent, detect, and delay progression of CKD.

\section{Acknowledgments}

We would like to thank the Renal Council of Puerto Rico for providing us pertinent data to make this study possible.

\section{Conflicts of interest}

The authors declare that they do not present any type of conflicts of interest that may affect the results and content in relation to this publication.

\section{Financing}

The research project did not receive specific funding.

\section{Ethical disclosures}

Protection of human and animal subjects. The authors declare that no experiments were performed on humans or animals for this study.

Confidentiality of data. The authors declare that they have followed the protocols of their work center on the publication of patient data.

Right to privacy and informed consent. The authors declare that no patient data appear in this article.

\section{References}

1. Cusumano AM, Rosa-Diez GJ, Gonzalez-Bedat MC. Latin American dialysis and transplant registry: experience and contributions to end-stage renal disease epidemiology. World J Nephrol. 2016;5:389-97.

2. Cusumano AM, González Bedat MC. Chronic kidney disease in Latin America: time to improve screening and detection. Clin J Am Soc Nephrol. 2008;3:594-600.

3. Cangiano JL. Hypertension and renal disease in Puerto Ricans. Am J Med Sci. 1999;318:369-73

4. Haddock L, Torres de Conty I. Prevalence rates for diabetes mellitus in Puerto Rico. Diabetes Care. 1991:14:676-84.

5. Colón-Pratts FM. Diabetes En Puerto Rico: Datos Sobre La Prevalencia, Incidencia y Mortalidad. Ponce, Puerto Rico: Revista Puertorriqueña de Medicina y Salud Pública Edición Especial; 2019. p. 14-22.

6. Centers for Disease Control and Prevention. Behavioral Risk Factor Surveillance System. [cited April 2020] Available from: https://www.cdc. gov/bloodpressure/index.html.

7. Cangiano JL. Hypertension in Hispanic Americans. Cleve Clin J Med. 1994:61:345-50

8. Mattei J, Tamez M, Ríos-Bedoya CF, Xiao RS, Tucker KL, Rodríguez-Orengo JF, et al. Health conditions and lifestyle risk factors of adults living in Puerto Rico: a cross-sectional study. BMC Public Health. 2018;18:491.

9. U.S. Department of Health and Human Services, National Institutes of Health, National Cancer Institute. Joinpoint Trend Analysis Software; 2020. Available from: https://www.surveillance.cancer.gov/joinpoint/ download. [Last accessed on 2020 May 12]

10. Cusumano AM, Garcia-Garcia G, Gonzalez-Bedat MC, Marinovich S, Lugon J, Poblete-Badal $\mathrm{H}$, et al. Latin American dialysis and transplant registry: 2008 prevalence and incidence of end-stage renal disease and correlation with socioeconomic indexes. Kidney Int Suppl (2011). 2013;3:153-6.

11. Rosa-Diez G, Gonzalez-Bedat M, Pecoits-Filho R, Marinovich S, Fernandez S, Lugon J, et al. Renal replacement therapy in Latin American end-stage renal disease. Clin Kidney J. 2014;7:431-6.

12. Just PM, De Charro FT, Tschosik EA, Noe LL, Bhattacharyya SK, Riella MC. Reimbursement and economic factors influencing dialysis modality choice around the world. Nephrol Dial Transplant. 2008;23:2365-73.

13. Pérez CM, Guzmán M, Ortiz AP, Estrella M, Valle Y, Pérez N, et al. Prevalence of the metabolic syndrome in San Juan, Puerto Rico. Ethn Dis. 2008;18:434-41.

14. Marcial JM, Altieri PI, Banchs H, Escobales N, Crespo M. Metabolic syndrome among Puerto Ricans and other Hispanic populations. P R Health Sci J. 2011;30:145-51.

15. Luxardo R, Kramer A, González-Bedat MC, Massy ZA, Jager KJ, Rosa-Diez G, et al. The epidemiology of renal replacement therapy in two different parts of the world: the Latin American dialysis and transplant registry versus the European renal Association-European dialysis and transplant association registry. Rev Panam Salud Publica. 2018;42:e87. 